\title{
A SIMULATION APPROACH TO THE EVALUATION OF OPERATIONAL COSTS AND PERFORMANCE IN LINER SHIPPING OPERATIONS
}

\author{
Aldo A. McLean \\ William E. Biles \\ Dept. of Industrial Engineering \\ University of Louisville \\ Louisville, KY 40292, USA
}

\begin{abstract}
This paper presents a simulation model of the operation of a liner shipping network that considers multiple service routes and schedules. The objective is to evaluate the operational costs and performance associated with liner shipping, as well as the impact of individual service schedules on the overall system. The approach proposes a discreteevent simulation model where shipping activities, container ship operations, and intermodal container movements are considered. The model allows for direct and transshipment operations of container cargo, and the evaluation of fuel consumption and other logistics metrics. The model is used to evaluate a liner shipping network consisting of four service routes, up to 64 container ships, and up to 20 ports with diverse physical characteristics and cost components. The results show the contribution of service routes, ports, container ships, and containers to the cost and performance of the system.
\end{abstract}

\section{INTRODUCTION}

Simulation modeling is an analysis method where computers are used to evaluate a model numerically in order to estimate the desired true characteristics of the model (Law and Kelton 2000). The nature of liner shipping processes is characterized by its dynamic operations and diversity of cost components. The dynamic behavior in liner shipping is characterized by the movement of containers. Containers are transported in container ships from port to port throughout one or more predefined service routes. The high costs in each activity and the large investments in assets are characteristics of these operations. However, the operational performance determines the quality of shipping service and the profitability of a service route.

A service route is a sequence of container ports with a deployed order of container ships that complies with strict fixed weekly schedules. These schedules are kept in place for a few months or for a year (Shintani et al. 2007). However, a unique service route cannot fully accomplish the objective of shipping cargo to a large number of destinations. A group of service routes forms a service network. In liner shipping, container cargos move through the network from their origin and a port of destination. Virtually any combination of origin-destination pairs is possible in the network when transshipment of cargo is allowed. Therefore, the configuration of the network is an important aspect to the performance and quality of the shipping activities. Evaluating the cost and performance of a service network and their individual components, where conditions are similar to the real operation, suggests opportunities for improvements and savings in operations.

Higher canal transit tolls, port fees, growing demand for liner services, and an expanding number of destinations suggest major challenges in modern liner operations. Perhaps one of the most important characteristics of the liner shipping industry is its high fixed cost (Haralambides and Veesnstra 2000). Despite improvement in the design and propulsion of container ships, the instability of prices for marine fuel oil is a major concern in the industry. Current prices oscillate between $\$ 550.00$ and $\$ 600.00$ per metric ton (pmt) based upon port locations. Cooperation and global alliance, the increasing use of transshipment operations and the size of container ships have helped the industry to be flexible and resilient. Determining the effects of these aspects in the performance of the shipping process is paramount to the design of new services and decision toward current ones.

This study describes the characteristics of a simulation model designed to mimic the operation of a liner shipping network. The Arena simulation package (Kelton et al. 2007) was used to code and run the model. An application case was proposed and solved using the model. The results show the expected operational cost and performance 


\section{McLean and Biles}

of the system in various aspects of shipping, including fuel consumption and logistics.

This paper is organized in six sections. Section 2 presents a previous work in liner shipping and simulation. Sections 3 and 4 present details of the simulation and logic model used represent and evaluate the network. A case scenario and results are presented in Sections 5 and 6, respectively.

\section{LITERATURE REVIEW}

Simulation modeling has been used effectively to evaluate determine the design and evaluate the operation of container ports in liner shipping. The operation of liners and their interaction with shipping process and service schedules has been the objective of recent simulation studies. A simulation approach that considered container ships and intermodal containers was presented in Van Rensburg, He, and Kleywegth (2005). They proposed a discrete-event simulation to evaluate events in liner shipping including voyage costs, fuel cost, and capital cost built in a modular fashion using $\mathrm{C}++$ functions. Goldsman, Pernet, and Kang (2002) used Arena to build a simulation model that included container ship, RORO, and break bulk operations to estimate the time required to move materials by a given number of ship. Lai, Lam, and Chan (1995) developed a model for shipping operations in the Europe-Middle EastFar East routes to evaluate several policies for allocation of containers. A simulation analysis of the advantage of fast ship services in liner shipping was presented in Ryan (1998). Bendall and Stent (2001) presented a simulation analysis applied to fleet design and deployment in liner shipping under hub and spoke networks. Simulation has been used to study inland waterway shipping processes in Swedish (1998) and Bush, Biles, and DePuy (2003).

Other studies have integrated service routes analysis and the allocation of container cargo. Song, Zhang, Carter, and Field (2005) measure the cost-efficiency of trade routes based upon the assignment of container cargo. Bendall and Stent (1999) evaluate trade routes for container ships to avoid reducing load factors. Baird (2002) evaluates the feasibility of transshipment operations in northern European routes.

Fuel consumption is an important aspect in shipping. Different approaches are used to model and evaluate the consumption and cost of containership operations. The approach in Eljard (2006) includes a set of equations that account for the specification of a container ship and cargo load conditions to forecast the actual fuel consumption in the vessel at a given sailing speed. Cullinane and Khanna (1998) present a set of equations to determine the fuel oil consumption (FO) base upon the average specific fuel oil consumption and power utilization. Shintani, Imai, Nishimura, and Papadimitris (2007) evaluate fuel and lubricant consumption using the specific consumption. That opera- tion of the vessel at lower speeds results in fuel savings because of the reduced water resistance is modeled by the cube rule (Stopford 1997). This relationship is used in Lo and McCord (1991) to suggest fuel oil savings using ocean current information.

\section{DESCRIPTION OF THE SIMULATION MODEL}

Rockwell's Arena software (Kelton et al. 2007) was used to develop the simulation model. The model evaluates the operation of liners, movement of intermodal containers, operation in ports, and the contribution of each service route and schedule to the operation of the network.

The model mimics the operation of container ships sailing and transporting containers between ports. Once a container ship arrives at a port, arrivals container cargo are offloaded and departing container are uploaded on the stowage area of the vessel. The rate at which this process takes place is set by the simulated turnaround rate of the port and the number of container assigned to the operation. The ship waits until the service period is completed to sail slowly out of the port. Once at sea, the container ship adopts the predefined service speed for the route segments in transit. A ship in a given route will adopt the predefined segment service speeds of the route until it reaches the anchorage area of the following port in the sequence. Significant container traffic is generated upon arrival of containers at origin ports. The process of a container ends once it reaches it destination port and exits the system. A container ship operates continuously until the end of the planning period. Multiple service schedules can operate together, and more than one ship of a different route can call at the same port at the same time.

The model was validated using round trip service proformas obtained from contributing liner operators. The results of the time performance in the simulation successfully matched the sailing, service, buffering, and docking time of voyage summary in proformas. A complete walkthough of the model, using the debug feature in Arena, and a visual analysis of model's Animation features complemented the models' validation and verification of the cost and operation of ports, containers, and container ships.

The model was divided into seven main sub-modules and three operational logics. The operation of each submodules are described next.

\subsection{Container Port Operations}

The main component of the model is its Generic Container Port Sub-module. This module has the objective of resembling activities and events that take place in a container port, such as berthing, service, and storage. Port Modules are easily configured to represent the basics characteristics of real container ports. Configurable parameters include some physical characteristics of ports. Length of access 


\section{McLean and Biles}

channel, storage capacity, and number of quay cranes are some of these parameters. In term of costs, container storage, stevedore, and container ship docking charges are included. Evaluation of time for shipping events, logistic results, and costs in the simulated liner process are evaluated in the generic module structures.

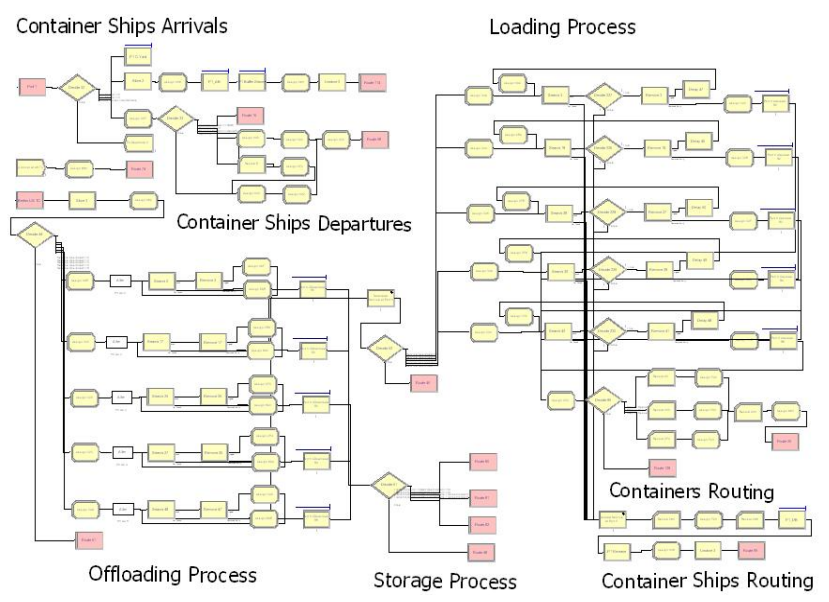

Figure 1: Port Module Structure

Figure 1 shows the basic structure of the model. Twenty such modules are available in the simulation. Port modules becomelunique after defining a name and arrival rate of container through the definition of the Port Assignment Table. The arrival of containers at port was modeled using exponential distribution with a choice of four levels of interarrival rates to simulating volumes. Distance between ports, including canals, are contained in the Distance Matrix. This distances are given in nautical miles (nm). Discrete events associated to port processes are the following:

1. Downloading: containers are offloaded from a container ship.

2. Storage: containers are stored in container port yards.

3. Uploading: containers are loaded to a container ship.

\subsection{Container Ship Operations}

Container ships are modeled as entities. A Container Ship Initialization Table sets up the initial physical and service parameters of container ships. These parameters include length overall (LOA), stowage capacity, consumption rate, maximum service speed, number of crew, minimum number of quay cranes required during service, and deployed service route assignments. A container ship's departure time and location at the beginning of the simulation are also defined in this table. The Ship Initialization table al- lows large flexibility to the model to represent different sizes, capacity, and speeds of container ships. Although any combination of container ships can be deployed, the current model offers the following container ship specifications:

Table 1: Container Ships Simulated Parameters

\begin{tabular}{|c|c|c|c|}
\hline $\begin{array}{c}\text { Capacity } \\
\text { (TEU) }\end{array}$ & Type & $\begin{array}{c}\text { LOA } \\
\text { (m) }\end{array}$ & $\begin{array}{c}\text { Service Speed } \\
\text { (knot) }\end{array}$ \\
\hline 9,600 & Post-Panamax & 295 & 24.7 \\
\hline 8,200 & Post-Panamax & 335 & 25.2 \\
\hline 4,895 & Panamax & 295 & 24.5 \\
\hline 4,738 & Panamax & 260 & 24.5 \\
\hline
\end{tabular}

The discrete events associated to the operation of container ships in the model are listed as follows:

1. Sailing: movement of container ship from a departing port to the next port in the sequence.

2. Anchorage: waiting for berthing.

3. Pilot in: sailing into port from anchorage to berth.

4. Service: moving containers off and on container ships.

5. Pilot out: sailing out of the port.

Container ships experience delays during sailing operation between consecutive ports. The delay distance was modeled using uniform distributed random variates in the range between 0 and $1 \%$ of the total segment distance.

\subsection{Service Route and Schedule Modules}

The model works under fixed weekly schedules and supports end-to-end routes exclusively. Service routes are controlled by the Service Route Sequence table to configuring up to five service routes and schedules with 20 ports sequence each. Service schedules are controlled by tables containing the Estimated Time for Arrival (ETA) and Estimated Time for Service (ETS). The ETA define the time for berthing and the expected length for service at port respectively.

In the model, links between two consecutives points (e.g. ports and canal points) in a service route are segments. It is assumed that container ships sailing a segment will adopt a predefined service speed. A Service Speed table is used to synchronize service schedules by defined service speeds for each segment of each service route in the network. 


\section{McLean and Biles}

\section{$2.4 \quad$ Intermodal Container Operations}

Container traffic is generated through a Demand Matrix table. This table stores a percentage of shipments required to be transported from an specific origin to each destination port in the network. The destination port is defined for each container after their arrival at originating ports. The Routing Table details the service route or path required to move container to their destination ports. Upon the arrival of containers at origin ports, destination port and transit paths are assigned to containers following the details in the Demand Matrix and Routing Tables. The discrete events associated to direct shipments operations of intermodal container operation are the following:

1. Arrival: containers arrive to their originating ports.

2. Storage: containers are stored before their departure.

3. Transport: containers are transported on container ships to their destination.

4. Exit: containers arrive to their destination.

\subsubsection{Transshipment Process}

Regularly, container transits require intermediate port stops before arriving to their final destinations. These intermediate ports are considered transshipment ports, and the required container storage during stops are transshipment storage (CTT1).

The simulation allows transshipment operations when one or two transshipment ports are required. The transshipment sequence is controlled by a two reference tables: Transshipment Routing and Transshipment Port tables. The first table controls the sequence of service routes to define a path for transshipment transports. The second stores a group of transshipment ports required to link any transit origin-destination pair. The discrete-events associated to transshipments operations are:

1. Arrival: arrival of containers to originating ports.

2. Storage: containers are stored before their first departure.

3. First Transport: containers are transported on container ship to their first transshipment port.

4. Transshipment Arrival: containers arrive to transshipment port.

5. Transshipment Storage: containers are stored during transshipment operations. (CTT1)

6. Second Transport: containers are transported on container ship to their final destination.

7. Exit: container arrive to their destination.

Upon arrival at the destination ports, containers immediately exit the shipping system. Statistics on exiting con- tainers are collected without considering storage or pickup procedures at ports.

\subsection{Canal Transit}

Canal transits are simulated through the Canal Points Structure. Canal Points manage scheduled transits through the Panama and Suez Canals and measure distance traveled, costs per transit, and time spent waiting before transiting canals. Distance between Canal Points and ports are defined by the Distance Matrix. Canal transit time is determined by the transit speed and specific channel distance. In the simulation transit speed for Panama and Suez are 5 and 6 knots while the length of the channels are 48 and 87 $\mathrm{nm}$ respectively. Figure 2 shows the structure of Canal Points as seen in the simulation model:
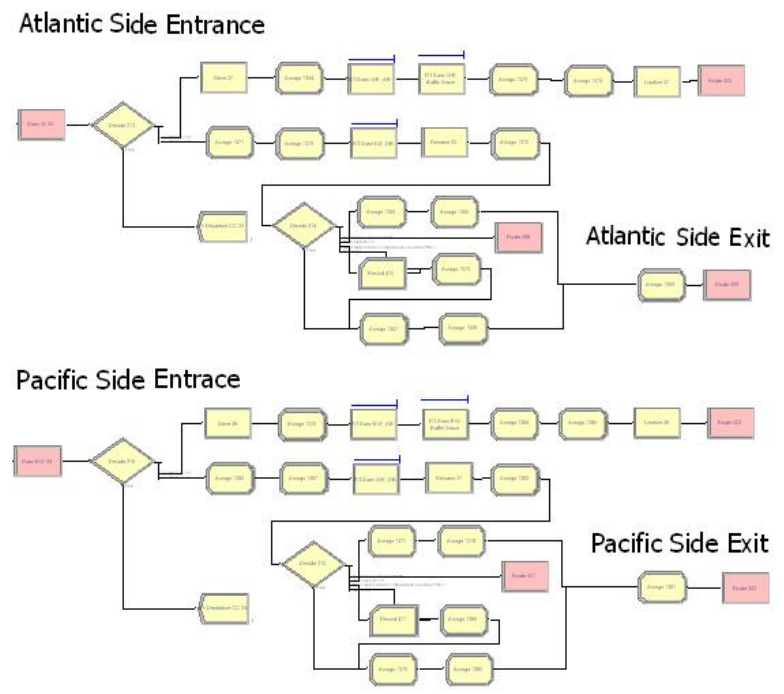

Figure 2: Canal Routing Structure (Panama Canal)

\section{SUPPORTING LOGICS}

The following logics supporting the evaluation of parameter of interest in the simulation model. The supporting logics evaluate consumption, logistic, and cost results.

\subsection{Consumption Model}

The approximation used to the consumption of fuel oil, diesel, and lubricants is applied on every container ship in the model. Shipbuilders define and supply the consumption rate of their ships measured in metric tons per day (mtd). The values of the consumption rate are assigned to each container ship through the Container Ship Initialization Table. The following list shows the consumption rate for container ships represented in the model: 


\section{McLean and Biles}

- $\quad 9,600 \mathrm{TEU}=248.2 \mathrm{mtd}$

- $8,200 \mathrm{TEU}=248.2 \mathrm{mtd}$

- $4,895 \mathrm{TEU}=156.6 \mathrm{mtd}$

- $\quad 4,795 \mathrm{TEU}=133.4 \mathrm{mtd}$

Fuel oil, diesel, and lubricant prices are specified for individual ports. Fuel oil and lubricant consumption are measured when container ships are at sea. For simplicity, their consumption is reported together. Diesel consumption is measured during anchorage and while these ships undergoes service at port with the assumption that auxiliary generators are used. The relationship between consumption and speed is modeled through the cube rule (Stopford, 1998). Equation 1 shows the general form of the cube rule. The exponent $a$ is set to be 3 .

$$
F=F^{*}\left(\frac{S}{S^{*}}\right)^{a}
$$

Where, $\mathrm{F}$ - current fuel consumption rate

$\mathrm{F}^{*}$ - designed fuel consumption rate

$\mathrm{S}$ - current service speed

$\mathrm{S}^{*}$ - designed service speed

\subsection{Logistic Model}

The logistic model describes a set of metrics designed to report various aspects of the operation of container ship, containers, and ports. The most representative metric in the model is the Network Operation Cost per TEU Transported and the Network Operation Cost per Hour. Other important indicators of the operation of container ship, port, and container are listed below:

- Total transit time

- Transit time, direct shipments

- Transit time, transshipments

- Storage time at ports

- Time at sea

- Miles traveled per ship

- Total vehicle miles traveled

- Number of moves at ports

- Container yard levels, TEU

- TEU transshipped per port

- Ships stowage utilization

- Departure Storage Time

- Transshipment Storage Time

- Ship stowage capacity utilization

- Total TEU delivered

\subsection{Cost Model}

The simulation model works under a cost model defined to account for main activities in liner shipping operations. The cost model proposed is divided into four main categories:

- Container ship related costs

- port related charges

- canal transit charges

- container related costs.

Container ship costs include all costs related to operation and maintaining the fleet. Fuel and diesel costs are determined for individual container ship and is determined from its consumption and the contracted price during operations. In container ships, cost and other charges are specific to each vessel. The cost for insurance, capital, crew, auxiliary, and maintenance are considered Fixed Costs. All ship related costs are defined individually per container ship regarding their physical characteristics.

Port related charges group stevedore, dockage, and container storage charges. Penalty costs are charged on container ships for overstaying outside the scheduled service time at ports. Storage charges vary based upon container ports and whether containers handled are full or empty, twenty or forty feet type. Three categories of the storage charges had been defined as storage before first departure, during first transshipment, and during second transshipment stop.

Canal transit costs are related to the charges per transits through the Panama and Suez Canals. Transit costs are evaluated per container ship visit and charges are estimated in a per TEU units base. Container costs include the lease cost for inter-modal container in the network in dollars per day of use.

All charges and fees are loaded into the model through global variable matrices and available throughout the evaluation run.

\section{CASE STUDY}

The current application describes a network of four service routes, 18 container ports, and 24 container ships. In addition, four transshipment routes, 29 port calls and four canal transits a week are considered. The service route and port call sequences for the case application are shown in Figure 3 and Table 2 respectively. 


\section{McLean and Biles}

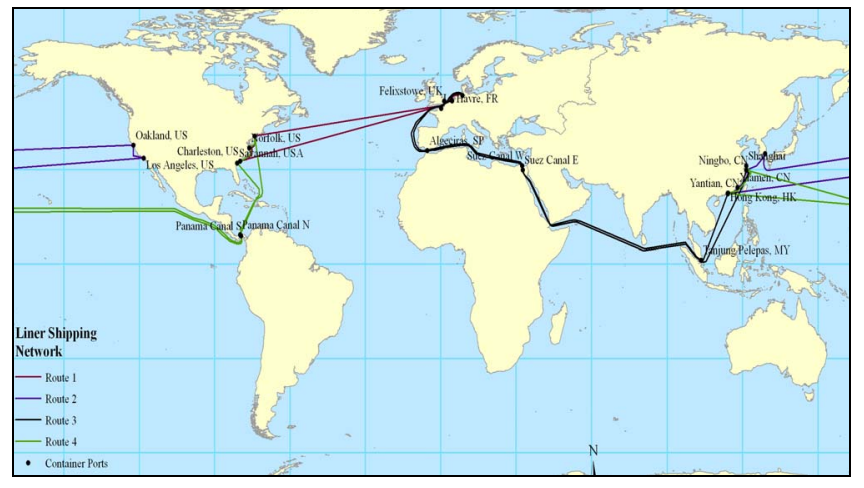

Figure 3: Service Routes

Four types of container ships are required to serve these schedules:

- Route R1 - 4 container ships of 4,895 TEU

- Route R2 - 5 container ships of 9,600 TEU

- Route R3 - 8 container ships of 8,200 TEU

- Route R4 - 8 container ships of 4,738 TEU

This application case assumes all four service routes and schedules will not change during the evaluation period and that ship deployments are fixed and container ships are not diverted at sea. It is assumed that distances between ports, price for fuel, diesel, and lubricants remain constant during the planning period. The application case assumes the following price structure:

Container ship cost

Fuel oil cost $=\$ 350.00 \mathrm{pmt}$

Diesel cost $=\$ 560.00 \mathrm{pmt}$

Lubricant oil cost $=\$ 1,000.00 \mathrm{pmt}$

Capital cost $=\$ 12.00$ per 14-ton slot per day (pd)

Insurance cost $=10 \%$ capital cost $\mathrm{pd}$

Crew cost $=\$ 500.00$ per crew member pd

Auxiliary cost $=\$ 50.00$ per crew member pd

Maintenance and repair cost $=5 \%$ of capital pd

Stevedore Charges

20 -foot loaded $=\$ 55.00$

20 -foot empty $=\$ 33.00$

40 -foot loaded $=\$ 82.50$

40 -foot empty $=\$ 49.50$

Dockage Charges

First $150 \mathrm{~m} \mathrm{LOA}=\$ 150.00$ per meter hours (pmh)

Additional LOA $=\$ 4.00 \mathrm{pmh}$

Overstaying $=\$ 4.00 \mathrm{pm} / 15 \mathrm{~min}$ units

Container Storage Charges

CPT first 7 days $=\$ 0.00$ per TEU-hour

CPT thereafter $=\$ 1.00$ per TEU-hour
CTT1 flat rate $=\$ 0.50$ per TEU-hour

Canal Transit Charges

Panama Transit $=\$ 54.00$ per registered TEU

Suez Transit Sub-PMX $=\$ 80.00$ per register TEU

Suez Transit Panamax $=\$ 56.00$ per register TEU

Suez Transit Post-PMX $=\$ 50.00$ per registered TEU

Transshipments

Felixstowe, UK, to Hong Kong, CN, via Norfolk, USA, in both directions

Algeciras, SP, to Charleston, USA, via Bremerhaven, $\mathrm{DN}$, in both directions

Table 2 shows the sequence of ports of call for each service route evaluated in the application. These routes were obtained form published schedules submitted by supporting shipping operators. The application did not include evaluations of container related costs. Operation cost and other logistic performance metrics are reported for the overall network and individual service routes.

Table 2: Service Routes and Sequences

\begin{tabular}{|l|l|l|l|}
\hline \multicolumn{1}{|c|}{ R1 } & \multicolumn{1}{c|}{ R2 } & \multicolumn{1}{c|}{ R3 } & \multicolumn{1}{c|}{ R4 } \\
\hline Rotterdam & Yantian & Bremerhaven & Ningbo \\
\hline Bremerhaven & Hong Kong & Suez W & Shanghai \\
\hline Le Havre & Los Angeles & Ningbo & Yantian \\
\hline Felixstowe & Oakland & Xiamen & Hong Kong \\
\hline New York & Pusan & Hong Kong & Panama S \\
\hline Norfolk & Ningbo & Yantian & New York \\
\hline Charleston & Xiamen & Tanjung P. & Norfolk \\
\hline- & - & Suez E & Savannah \\
\hline- & - & Algeciras & Panama N \\
\hline- & - & Rotterdam & - \\
\hline
\end{tabular}

\section{SIMULATION RESULTS}

A total of twenty replications of three months each was sufficient to produce good statistical precision of the results in the liner shipping network. The model run satisfied a $95 \%$ confidence on the mean value for the Network Operation Cost per TEU Transported and the Network Operation Cost per Hour of Operation measures. Results for the overall network and individual service routes are reported in the following lines.

\subsection{Assessment on the Network Operation}

The network operation summary shows an average Operation Cost of $\$ 419.581$ million in three months of operations. The largest contributor to the operation cost is the Fixed Cost, $\$ 258.243$ million, representing a $62 \%$ of the Operation Cost of the network. The second largest is Fuel Oil Cost at $\$ 78.661$ million or $19 \%$ of the Operation Cost. 


\section{McLean and Biles}

A key indicator is the Network Operation cost per TEU was \$977.69 dollars per TEU, obtained after delivering an average 429,156.40 TEU of cargo during the assessment period. The Network Operation Cost per Hour of Operation showed $\$ 7,530.52$ per hour in the network.

The summary also reveals $10 \%$ for Stevedore Cost, handling containers off/on container ships. Canal transits represent $5 \%$ of the operation cost at $\$ 20.073$ million. Storage cost was $4 \%, \$ 15.442$ million, driven by the cost of retaining containers before their first departure or CPT at \$15.111 million and storage during transshipment procedures or CTT1 at $\$ 0.330$ million.

Regarding the operation time, the most notable result is the sailing time of $74.5 \%$ of the network's time. Service of container ships at ports accounts for $11.7 \%$ of the network time while transits through Panama and Suez Canals represent $2.8 \%$ of the time.

Fuel consumption results reveal a consumption of $224,746 \mathrm{mt}$ of fuel oil during the quarter. A total of 4,295 $\mathrm{mt}$ of diesel oil was consumed in the operation of auxiliary engines at buffers and berths by the fleet.

Regarding the utilization of the stowage capacity of container ships, the highest average utilization in the fleet was experienced on CC 17 and CC 18. These vessels belong to service route $\mathrm{R} 1$, having a registered capacity of 4,895 TEU. Their average utilization reached over $85 \%$ with a maximum observed occupancy of $100 \%$. The lowest average utilization was $50.1 \%$ observed in CC9 and CC4. Both container ships belong to service route R3 with capacity of 8,200 TEU. Despite of their low utilization, CC4 reached $93.2 \%$ of its total capacity utilization while CC9 reached $89.5 \%$ of its total capacity at some point during the evaluation period.

Results on the logistic performance also show an average container transit time of 23.38 days. This transit time includes both direct and transshipment time of 23.16 days and 51.28 days, respectively. The longest time observed during a direct shipment was 67.50 days. Likewise, the longest time observed for transshipment was 81.50 days. Containers spent an average of 5.06 days in container yards at ports. During the evaluation, 43.89 days was observed for some containers. On average, containers spent 12.07 days for transit at sea. A maximum high of 25.24 days at sea was observed in this period.

The port of Bremerhaven accounts for 4,743.00 TEU, and the port of Norfolk handled 2,145 TEU, both as transshipment ports.

\subsection{Assessment of Individual Service Routes}

Table 3 summarizes details of the results and overall operation of service routes (R1, R2, R3, R4) in three aspects: cost, productivity, and performance. Service schedule R1 handled $22 \%$ of cargo throughput consuming only $11 \%$ of the cost in the system. Service schedule R2 is yield to $33 \%$ of throughput and $25 \%$ of the total operation cost. The $29 \%$ of delivered TEUs in service route R3 is offset by its share in operation cost of $39 \%$. The lowest rate of deliveries is found in R4 with $16 \%$ and operation cost of $26 \%$.

Table 3: Service Routes and Schedule Contribution

\begin{tabular}{|c|c|c|c|}
\hline Service & $\begin{array}{c}\text { Operation } \\
\text { Cost }\end{array}$ & Vehicle-miles & $\begin{array}{c}\text { TEU } \\
\text { Delivered }\end{array}$ \\
\hline R1 & $11 \%$ & $13 \%$ & $22 \%$ \\
\hline R2 & $25 \%$ & $20 \%$ & $33 \%$ \\
\hline R3 & $38 \%$ & $32 \%$ & $29 \%$ \\
\hline R4 & $26 \%$ & $36 \%$ & $16 \%$ \\
\hline
\end{tabular}

In terms of vehicle-miles traveled, R4 and R3 are the service routes with the highest performance. The vehiclemiles traveled measure the total distance traveled during the evaluation period. Therefore, the low performance in $\mathrm{R} 1$ and R2 is caused mainly by the number of container ships assigned to these routes, four and five respectively.

\section{CONCLUSION}

The results for a three-month analysis of the operation of the liner shipping network reveals operation costs, transit time, and container ship utilization consistent with quarterly reports in liner shipping industry. The results show details on the expected performance of a liner shipping network and service schedule can be analyzed through simulation modeling. Simulation modeling can be used to analyze the effects and contribution of each party when a global alliance and cooperation between firms is proposed. Likewise, it can be used to determine areas were the performance is above and below the expected level of operations in shipping.

The next step in this research would include optimization of the overall network performance by changes in individual service routes and support for refueling plan analysis for container ship in service.

This research contributes to the knowledge base in liner shipping by proposing a modeling approach where the dynamic operation of service routes, deployment, and scheduling decision in liner shipping are explored under a realistic container transit scenario.

\section{ACKNOWLEGMENTS}

The authors thank the Department of Industrial Engineering and the Department of Geography of the University of Louisville for their logistic support as well as the liner shipping firms interviewed during the research process. 


\section{REFERENCES}

Baird, A. 2002. The Economics of Container Transshipment in Northern Europe. International Journal of Maritime Economics, 4, 249-280.

Bendall, H. B., and A. F. Stent. 1999. Longhaul feeder services in an era of changing technology: An AsiaPacific perspective. Maritime Policy \& Management, 26(2), 145-159.

Bendall, H. B., and A. F. Stent. 2001. A Scheduling model for a High Speed Container Service: A Hub and Spoke Short-Sea Application. International Journal of Maritime Economics, 3(3), 262-277.

Bush, A., W. E. Biles, and G. W. DePuy. 2003. Interative Optimization and Simulation of Barge Traffic on an Inland Waterway. In Proceedings of the 2003 Winter Simulation Conference, 1751-1756.

Cullinane, K., and M. Khanna. 1998. Economies of Scale in Large Container Ships. Journal of Transportation Economics and Policy, 33(2), 185-208.

Eljardt, G. 2006. Development of a Fuel Oil Consumption Monitoring System. Ph.D. thesis, Technische Univesität Hamburg-Harburg.

Goldsman, D., S. Pernet, and K. Kang. 2002. Simulation of Transportation Logistics. In Proceedings of the 2002 Winter Simulation Conference, ed. E. Yucesan, C.H. Chen, J. L. Snowdown, and J. M. Charnes, 901-904.

Haralambides, H. E., and A. W. Veenstra. 2000. Modeling performance in liner shipping. In K.J. Button and D.A. Hensher: Handbook of Transport modeling. Pergamon-Elsevier Science.

Kelton, W. D., R. P. Sadowski, and D. T. Sturrock, 2007 Simulation with Arena, $4^{\text {th }}$ Edition, McGraw-Hill, New York

Lai, K. K., K. Lam, and W. K. Chan. 1995. Shipping containers logistics and allocation. Journal of the Operational Research Society, 46, 687-697.

Law, A. M., and W. D. Kelton. 2000. Simulation Modeling and Analysis. Third Edition. McGraw-Hill.

Shintani, K., A. Imai, E. Nishimura, and S. Papadimitriou. 2007. The Container Shipping Network Design Problem with Empty Container Repositioning. Transportation Research: Part E, 43(1).

Song, D., J. Zhang, J. Carter, T. Field, J. Marshall, J. Polak, K. Schumecher, P. Shina-Ray, and J. Woods. 2005. On Cost-Efficiency of the global container shipping network. Maritime Policy and Management, 32(1), 15-30.

Stopford, M. 1997. Maritime Economics. Chesham, Buckinghamshire: Pointing-Green Publishing Services.

Swedish, J. A. 1998. Simulation of an Inland Waterway Barge Fleet Distribution Network. In Proceedings of the 1998 Winter Simulation Conference, ed. D. J.
Medeiros, E. F. Watson, J. S. Carson, and M. S. Manivannan, 1219-1221.

Van Rensburg, J. J., J. He, and A. J. Kleywegt. 2005. A computer simulation model of container movement by Sea. Proceedings of the 2005 Winter Simulation Conference, ed. M. E. Kuhl, N. M. Steiger, F. B. Armstrong, and J. A. Joines, 1559-1566.

\section{AUTHOR BIOGRAPHIES}

ALDO McLEAN is an Instructor in the Department of Industrial Engineering at the University of Louisville. He spent eight years working in consumer electronics and telecommunication industries. He has experience related to engineering and management for global firms include LG Electronics, Siemens, NEC, and Panasonic. He developed expertise in logistics, quality improvement, and engineering management. His current research interests include transportation logistics, simulation modeling, and operation management. He earned is Ph.D. in Industrial Engineering in 2008. His e-mail address is

aldo.mclean@louisville.edu.

WILLIAM E. BILES is the Clark Chair of Computer Aided Engineering in the Department of Industrial Engineering of the University of Louisville. He spent two years in the US Army and seven years in industrial R\&D before undertaking an academic career. He has held academic appointments at the University of Notre Dame, Penn State, Louisiana State University, and the University of Louisville. Dr. Biles received the Distinguished Engineering Alumnus award from the University of Alabama in Huntsville in 2004. His most recent publication is "Environmentally Benign Manufacturing" Chapter 1 in the 2007 John Wiley handbook for Environmentally Conscious Manufacturing. His e-mail address is

webile01@louisville. edu. 